\title{
?1
}

TI 2021-041/VII

Tinbergen Institute Discussion Paper

\section{Leaders, Factions and Electoral Success}

Benoit S Y Crutzen ${ }^{1}$

Sabine Flamand ${ }^{2}$

${ }^{1}$ Erasmus Universiteit Rotterdam

2 Universitat Rovira I Virgili and CREIP 
Tinbergen Institute is the graduate school and research institute in economics of Erasmus University Rotterdam, the University of Amsterdam and Vrije Universiteit Amsterdam.

Contact: discussionpapers@tinbergen.nl

More TI discussion papers can be downloaded at https://www.tinbergen.nl

Tinbergen Institute has two locations:

Tinbergen Institute Amsterdam

Gustav Mahlerplein 117

1082 MS Amsterdam

The Netherlands

Tel.: +31(0)205984580

Tinbergen Institute Rotterdam

Burg. Oudlaan 50

3062 PA Rotterdam

The Netherlands

Tel.: +31(0)10408 8900 


\title{
Leaders, Factions and Electoral Success*
}

\author{
Benoit S Y Crutzen ${ }^{\dagger}$ \\ Erasmus Universiteit Rotterdam \\ Tinbergen Institute
}

\author{
Sabine Flamand ${ }^{\ddagger}$ \\ Universitat Rovira i Virgili \\ CREIP
}

This draft: April 9, 2021

\begin{abstract}
We develop a formal model of the internal game between the leader and the factions of a party, to study the effect of party leadership on electoral success. Factions are of interest or of principle. The probability of winning an election is increasing in the leader's charisma, but also in party unity and coherence and in the factions' total contributions to party work and electoral efforts. To push factions to contribute, the leader offers both types of factions their favorite rewards in exchange for their contributions. We show that party unity and factions' total contributions are not necessarily increasing in the leader's charisma and ideological proximity to factions. Further, we show that factions of interest constraint the party's electoral strategy less than factions of principle. In particular, factions of interest always contribute more than factions of principle, are less of an obstacle towards achieving party unity, and offer the party more freedom in its choice of the ideological location and charisma of the party leader.
\end{abstract}

${ }^{*}$ We are indebted to participants at several seminars, workshops and conferences for their insightful comments and suggestions.

${ }^{\dagger}$ Email: crutzen@ese.eur.nl

${ }^{\ddagger}$ Email: sabine.flamand@urv.cat 


\section{Introduction}

Electoral success and policymaking are the overarching priority of any mainstream party. To meet this goal, parties follow multi-faceted strategies. To deepen our understanding of the forces that shape these strategies, we need to analyse not only the characteristics of the electoral arena parties are in, but also the inner workings of parties themselves. It is on the inner workings of parties that this paper focuses on.

Our premise is that parties are aware that voters value ideological proximity (Downs 1957; Enelow and Hinich 1982), contributions by factions and activists (Aldrich 1983; Schofield 2003), party unity and coherence behind the party leader and manifesto (Greene and Haber 2015) and charismatic leaders (Schofield 2003; Bittner 2011; Cross and Pilet 2015). ${ }^{1}$ These four characteristics of a party are essential in determining its electoral success: an ideologically appealing leader and platform can be quickly undermined if the party does not defend and stand united behind its leader and platform (Snyder and Ting 2002; Dewan and Myatt 2007, 2008; Andeweg and Thomassen 2011; Ceron 2012; Vivyan and Wagner 2012; Marx and Schumacher 2013; Buttler and Powell 2014; Greene and Haber 2014, 2015). Tony Blair was an asset for New Labour in the 1997 election precisely because he managed to convince his party to unite behind him and the platform he was defending was particualrly appealing to the British electorate of the time (Dewan and Myatt 2007). In the USA, think of Obama's 2008 campaign. By generating enthusiasm, goodwill and hope under his "Yes we Can" campaign slogan, Obama's charisma created precisely such a united front behind him. To the contrary, Hillary Clinton did not manage to tame down and control the dissenting voices within her party, especially those coming from the left wing ideological side of the party and from Bernie Sanders in particular. Voters were also sceptical about her and her electoral platform, as she admits herself in her account of her presidential defeat (Clinton, 2017).

In line with the above examples, we wish to understand better how the charisma and

\footnotetext{
${ }^{1}$ Given that our theory rests on the ideological internal heterogeneity of parties, our theory speaks to mainstream parties with a relatively broad appeal, rather than niche and extreme parties, which are typically, though not always, ideologically much narrower and homogeneous.
} 
ideological position of a party leader interact inside the party with the decisions of other key party players - especially party factions - to determine that party's electoral success. We give factions center stage because, very often, a party's prominent figures are the top members of a faction (Bettcher 2005; Persico, Pueblita and Silvermann 2011; Ceron 2012; Dewan and Squintani 2016). Factions are thus one of the key actors within parties.

We develop a formal theory of parties as complex, multi-agent organisations (Laver and Benoit, 2003; Laver and Schofield, 1990). The game we analyse is that of a mainstream party — such as the US Republicans and Democrats or the U.K.'s Labour and Conservatives - which has to choose at its annual conference a new leader, knowing that this leader then needs to strike an agreement with the different party factions to ensure that both party work and the general election strategy are carried out and supported as well as possible. We model the relationship between factions and the leader as a Tullock (1980) contest game in which the leader offers factions some rewards in exchange for their contributions. To the best of our knowledge, our model is the first to analyse the effects of leadership strength on factional choices and party unity, which in turn determine electoral success.

We consider two types of factions. ${ }^{2}$ They can be either of principle or of interest, to follow the terminology of Bettcher (2005). Factions of principle are ideological in nature and wish to influence the party manifesto, to reap 'collective benefits' from the exchange with the leader. Examples of such factions were evident in U.K.'s Labour in the eighties or the Australian Labor Party (Brand, 1989; McAllister, 1991) and in France's Socialist party before their dismal defeat in 2017, an example we return to later on. They are currently very visible in U.K.'s conservative party as a result of Brexit. Factions of interest wish to obtain party funds or other 'selective benefits', allowing them to continue developing and sustaining their activities, as was the case for Chicago's Daley machine or Italy's Democrazia Cristiana.

There is a key difference between these two types of factions that we build upon. A

\footnotetext{
${ }^{2}$ Many preceding contributions also group factions into two main types; see for example Janda (1980), Panebianco (1988), Bettcher (2005), Konig (2006), Persico et al. (2011) and Dewan and Squintani (2016).
} 
faction of interest does not care directly about which factions get the funds they did not manage to secure for themselves, as the allocation of these other funds does not impact its activities directly. To the contrary, a faction of principle cares directly about the total distribution of influence across all factions, as the latter determines the overall electoral message the party sends to voters, and thus can interfere directly with the faction's own plans. In the terminology of formal modelling, the objective function of factions of principle exhibits externalities, which are absent from the objective function of factions of interest.

We also consider two types of leader: strong and charismatic or weak and dull. Our definition of charisma is that of authority charisma: an individual is authority charismatic when its charisma's first purpose is to have followers abide by their leadership. ${ }^{3}$ Well known examples of authority charismatic leaders, on top of those mentioned earlier, include Baroness Thatcher and General De Gaulle. Obviously, voters value charismatic leaders more than dull ones. This is the bright side of having a charismatic leader. Yet, authority charismatic leaders can bias the exchange game they play with factions in favour of those they prefer, as they can use their authority and electoral appeal as a lever to give their views prominence (Dewan and Myatt 2008; Schumacher, de Vries and Vis (2013); Landa and Tyson 2017, Bittner 2011). This is the dark side of authority charisma. Thus, the contest among factions is fair and unbiased under a weak leader. To the contrary, a charismatic and strong leader biases the game in favour of those factions that are closest ideologically to them. These factions end up receiving a fraction of the rewards that is larger than what their contribution would command.

This effect of the leader's charisma on the relationship with factions is supported by empirical research. For example, Ceron $(2012,2019)$ provides strong support for the idea that "factions negotiate over party positions according to the bargaining power of each subgroup." His key finding is that factions affect the party manifesto proportionally to

\footnotetext{
${ }^{3}$ Weber (1968, chapter 6) is among the first to discuss this concept. He remarks that this type of charisma can serve the organisation - the party, here - only if the leader aligns the effects of their charisma with the objectives of the organisation. As in our theory the party selects the leader to maximise its chances of winning the forthcoming election, such a need is automatically satisfied in our case. For a recent popular report on charisma and authority charisma, see BBC (2017).
} 
their strength. ${ }^{4}$ Yet, Ceron also finds that this proportionality is weakened when leaders have a degree of autonomy from the parliamentary party and thus can bias the distribution of factional influence to their liking. As strong and charismatic leaders find it easier than weak leaders to be granted more autonomy inside their party, his findings thus justify and rationalise our modelling strategy.

We follow the literature on valence politics to model the extent to which the party appears united behind its leader via both the factions' contributions and their influence or activities (Miller and Schofield 2003; Schofield 2003, 2006; Schofield and Sened 2005). A party achieves unity only when the distribution of the contributions (and rewards) of the different factions is monotonically decreasing in the ideological distance between the leader and the different factions. Indeed, if the most active faction is the one that is ideologically most distant from the current leader, the message the party is sending to voters is very unclear, not to say outright contradictory. Such a situation can only be electorally costly for that party. A vivid example of such a suboptimal situation is offered by the French Socialist party in the June 2017 Presidential election, during which the leader that the party had chosen in its primary a few months earlier - Benoit Hamon, a markedly left wing candidate - found himself competing intensely and vocally with Manuel Valls, the head of the most centrist faction in that party. Another important example is the 2016 Presidential election fight within the Democratic party between Hillary Clinton and Bernie Sanders.

That diverse and possibly contradictory influences on the party manifesto can reduce its coherence is self-evident. That the activities of factions of interest also impact the party's image less so. But they do, as they have the scope and ideological colour of the faction carrying them out - think of the trading of votes for jobs under Daley's Chicago machine or the public jobs the different factions within Italy's Christian Democratic party Democrazia Cristiana were fighting over (Bettcher 2005; Persico et al. 2011).

Tuning to our results, we find that charisma generates a trade-off between faction contributions and party unity. For any given ideological position of the leader and factions,

\footnotetext{
${ }^{4}$ Lo, Proksch, and Slapin (2014) offer similar evidence.
} 
weak leaders are always associated to higher faction contributions than charismatic ones. Yet, weak leaders can never deliver strong party unity. Indeed, party unity is weak with factions of interest, as all factions contribute equally and receive the same share of funds. To the contrary, party unity is totally absent with factions of principle, as only the most ideologically extreme factions exert some effort and their contradictory influence on the manifesto generates an incoherent message to voters. Therefore, weak leaders may be preferred to strong and charismatic ones only in an electoral system that rewards a high level of contributions and ideological proximity of the leader to the median voter - weak leaders, no matter their ideology, do not influence the behavior of factions - but does not value much charisma and party unity and coherence.

The type of party factions matters in other respects. In particular, factions of interest are more conducive to electoral success than factions of principle. Indeed, factions of interest always contribute more than factions of principle. ${ }^{5}$ Furthermore, party unity is stronger with factions of interest. Finally, with factions of principle, there is a trade-off between maximising total contributions and having at least some party unity when the leader is strong and charismatic. Such trade-off is absent with factions of interest.

An important consequence of our findings is that parties with factions of interest should be more prone to sustain electoral systems that allow for more personalisation of the electoral contest. Our theory thus suggests the existence of a causal link between the internal characteristics of parties and the type of electoral system these parties favour. Finally, the above findings imply that, when it comes to the choice of the party leader and manifesto, we should expect parties to respond and adapt more easily to changes in the position of the median voter when factions are of interest.

The rest of the paper is structured as follows. The next section reviews the related literature. Section three presents the model. Section four solves for the optimal behaviour of factions. The following section considers the party's optimal choice and its consequent electoral success. The last section discusses our findings and concludes. All proof are

\footnotetext{
${ }^{5}$ The measure we use to compare contributions across faction types is their contributions as a fraction of the reward available to them.
} 
relegated to the appendix.

\section{Related Literature}

The main goal of our analysis is to study how a party leader's type and ideological position jointly impact the willingness of different types of factions to contribute to their party's work and electoral strategy and thereby its electoral success.

We build on three strands of the existing literature. First, we borrow from the literature on valence politics and the personalisation of politics the idea that strong and charismatic leaders bring about an electoral bonus, all else equal. Important contributions are Schofield (2003), Bittner (2011) and Cross and Pilet (2015). For example, Schofield (2003) builds a formal model that adds to the literature on spatial electoral competition by letting the party leader be of high or low valence, and Bittner (2011) shows empirically that the charisma of leaders - as opposed to their competence, for example - is the most important factor determining success in elections. Recently, Wauters et al. (2016) also show that, at least in the Belgian flexible proportional system, the personalisation of politics seems to be increasingly limited to party leaders, in line with our working assumption that having a strong and charismatic leader is an electoral advantage, all else equal. We add to this literature by suggesting two additional consequences of having a strong and charismatic leader that may be important for the electoral score of a party: factional contributions are lower under a strong leader, but the degree of internal unity can be higher with such leaders.

Second, we also take seriously the idea of the literature on valence politics that a party's main activists and factions are key to determine the party's electoral fortunes. See for example Miller and Schofield (2003), Schofield (2006) and the literature that builds on these articles, such as Schofield and Sened (2005); Karp, Banducci, and Bowler (2007); Schofield et al. (2011) and Kernell (2015). ${ }^{6}$ Schofield (2003) states that "[b]y

\footnotetext{
${ }^{6}$ Aldrich (1983) is one of the very first formal models that includes activists, yet in that article activists do not influence the platform of the party.
} 
contributing time and money to the candidate, activists allow the candidate to advertise his (or her) policies and persuade otherwise uncommitted voters that the candidate is a suitable choice." Our contribution here is to allow factions to be of one of the two main types - namely of interest or of principle, following Bettcher (2005) and Persico et al. (2011) - to study the willingness of different types of factions to contribute under different types of leaders.

Third, our formal theory contributes to the literature on the electoral consequences of party unity by suggesting one mechanism through which the interactions between the position and type of the leader and that of the factions map into the degree of party unity that can be achieved. Caillaud and Tirole $(1999,2002)$ were among the first to propose a formal model in which disagreement among factions can reduce the electoral appeal of the party, but their theory offers no explicit role for the party leader and his views. Other formal theories which focus on the effects of disagreements among factions are Hortala-Vallve and Mueller (2015) and Mutlu-Eren (2015). In these contributions it is the effect of party splits that takes centre stage. Dewan and Myatt (2007 and 2008) are contributions which focus on the role and effects of the characteristics and choices of a party leader, but in their theory factions play not explicit role. Our results also resonate with those of Dewan and Squintani (2018), even though our model is very different from theirs. Invernizzi and Prato (2019) also develop a formal theory of how a party leader can incentivize (two) factions to contribute to the party's electoral efforts. They do not distinguish explicitly between factions of interests and of principle and they have only one type of leader. They focus on the relationship between the characteristics of the electoral system and the optimal shape of the function governing the allocation of power across factions.

Empirical exercises in this strand of the literature include Andeweg and Thomassen (2011), Ceron (2012), Vivyan and Wagner (2012), Marx and Schumacher (2013), Buttler and Powell (2014) and Greene and Haber (2014 and 2015). Greene and Haber (2015) offer empirical backing to our contribution as they provide evidence that party disunity is viewed negatively by voters, all else equal. 
Finally, we contribute to the advancement of our understanding of which party characteristics make parties more or less reactive to changes in the environment they are embedded in (Schumacher et al. 2013) and more or less favorable to electoral systems that give more prominence to their key players, especially their leader (Cross and Pilet, 2015; Wauters et al., 2016)

\section{The Model}

We consider a game between a party leader and factions in a setting where voters favour a party: 1) that is close to them ideologically (Downs, 1957); 2) whose leader is charismatic (Bittner, 2011); 3) that offers a coherent platform and that appears united behind its leader (Greene and Haber, 2015); and 4) in which factions contribute to party work (Schofield 2003). Thus, when choosing its leader, the party takes into account not only the direct electoral consequences of the leader's ideological position and type, but also their indirect consequences on party unity and factional contributions.

Leaders are characterized by an ideology and a degree of authority charisma. Authority charisma is defined as someone's capacity to have followers or subordinates obey their command. ${ }^{7}$ The leader's ideology is $L \in[0,1]$, which is also the ideological location of the party manifesto. The leader's authority charisma can be weak or strong. Whenever the leader is charismatic, the party receives an electoral boost. The leader wishes to give prominence to the views that are in line with theirs. ${ }^{8}$ An authority charismatic leader is in a position to do this, whereas a leader with weak charisma is not. In other words, authority charisma allows the leader to favour the factions with an ideology that is close to theirs.

Party factions are of two types. Factions of principle are populated by politicians motivated by ideology, while factions of interest are populated by politicians motivated by the desire to obtain personal benefits (in our case, party funds). While factions of

\footnotetext{
${ }^{7}$ See Weber (1968, chapter 6) and BBC (2017).

${ }^{8}$ See for example Schelling (1978) and Benhabib, Bisin and Jackson (2011) on the pervasiveness of such homophily in very diverse environments.
} 
principle would like to craft the party manifesto in line with their ideology, factions of interest would like to get party funds to carry out their factional activities. There are three equally-sized factions of each type, labelled $A, B$ and $C{ }^{9}$ Each faction is characterised by an ideological position on the ideological spectrum: $A$ has its ideological bliss point in 0 ; $C$ has it in 1 and that of $B$ is somewhere in $[0,1] .^{10}$

To incentivize factions to contribute to the party's strategy and goals, the leader sets up two exchanges with factions, one per faction type. ${ }^{11}$ In the exchange with factions of interest, the leader offers party funds worth $V$ in exchange for the factions' contributions. The leader's type does not influence $V{ }^{12}$ These funds can then be used by the different factions to finance their own activities. In the exchange with factions of principle, the reward offered to factions in return for their contributions is influence on a share $I$ of the party manifesto. $I$ is the share of that part of the party manifesto all players involved expect their party to be able to implement after the election (provided all players behave according to the rules of the game and in accordance with the incentives provided to them). Even though we do not model explicitly this part of the game, for the sake of simplicity, I can be thought of as being pinned down as follows by the party leader. Given the current information about how the election is likely to go and given how each faction is expected to play the game in equilibrium, the party leader can estimate how

\footnotetext{
${ }^{9}$ Allowing factions to differ in size/power would generate the results that Ceron (2012) uncovered empirically, namely that more powerful factions would benefit more from the exchange with the leader. We abstract from this effect for the sake of simplicity only.

${ }^{10}$ The reason why factions of interest have an ideological color too is simply that the actions they undertake are obviously in line with their views.

${ }^{11}$ We split the exchange between the leader and the factions into two different contests for the sake of expositional ease. Indeed, as the goals of the two types of factions differ and so do the rewards available, the choices of one set of factions does not influence directly the choices of the other set of factions. Thus there is not too much loss of generality in splitting the exchange the way we do.

${ }^{12}$ In line with the available empirical evidence, see for instance IDEA (2013), we view these funds as being determined mainly by the party's performance at the previous election, and thus factions realize that their choices regarding their current contribution to party work cannot influence the value of $V$, which is predetermined at the moment they make their choice. Assuming that the amount of available party funds under a strong leader is at least as large as that available under a weak leader reinforces all the results that follow. Also, allowing factions to care directly about the electoral perfomance of their party in the election would only generate an across the board increase in effort by factions. We abstract from this effect for the sake of simplicity and also to make it easier to compare equilibrium behavior across faction types.
} 
well the party is likely to do in the election, and thus how much influence it will have on government. This in turn allows the leader to pin down $I$ as the solution to the fixed point problem between each faction's contribution strategy as a function of $I$ (and the other relevant parameters in the game) and the expected electoral success of the party, which determines its influence on government and thus $I$. Again for the sake of simplicity and ease of exposition, the leader's type does not influence $I{ }^{13}$

Let $c_{i}$ be faction $i$ 's contribution to the party. In the spirit of Tullock (1980), the mapping governing the exchange is given by the following standard imperfectly discriminating contest success function:

$$
S h_{i}=\frac{b_{i} c_{i}}{\sum_{j=A, B, C} b_{j} c_{j}}
$$

where $S h_{i}$ is faction $i$ 's share of party funds or party manifesto influence and where the different $b_{i}$ 's are the weights the leader uses in evaluating each faction's contribution to party work. All weights are between zero and one. The closer to one is $b_{i}$, the more the leader favours faction $i$. The leader's capacity to bias the exchange with factions is a function of the leader's charisma. If the leader is weak, the exchange with factions is unbiased and $b_{i}=1$ for all $i=A, B, C$. If the leader is strong, the exchange is biased and the biases the leader uses are given by one minus the Euclidean distance between the leader's ideological position $L$ and that of any faction $i$. Let $L \in[0,1 / 2]$ (the biases are defined symmetrically for $L \in(1 / 2,1])$. These biases are given by:

- If $B \geqslant L$ :

$$
\begin{aligned}
& b_{A}=A-L=1-L \\
& b_{B}=1-B+L \\
& b_{C}=L-C=L
\end{aligned}
$$

\footnotetext{
${ }^{13}$ Assuming that a weak leader opens to influence at least as large a share of the manifesto as a strong leader, which would seem the obvious assumption to make in case we wish $I$ to depend on the type of leader in charge, reinforces all the results that follow.
} 
- If $B<L$ :

$$
\begin{aligned}
b_{A} & =A-L=1-L \\
b_{B} & =1-L+B \\
b_{C} & =L-C=L
\end{aligned}
$$

Without some form of compensation, factions do not contribute to their party beyond a certain level. This is why the party leader enters in an exchange with the party factions. While there may be diverse reasons why factions may need to be compensated to follow their leader's desires and choices, we capture this aspect of the problem by assuming that factions bear a strictly positive cost for their contributions - for the sake of simplicity only, we actually set this cost equal to the contribution itself - and thus normalize to zero the minimal contribution factions are willing to offer for free (such a minimal contribution can also be thought of as the contribution factions offer given the baseline expectation of how well the party will fare in the election if no further help and contribution is offered). Thus, in the exchange with factions of interest, faction $i=A, B, C$ solves the following problem:

$$
\max _{c_{i}} \frac{b_{i} c_{i}}{\sum_{j=A, B, C} b_{j} c_{j}} V-c_{i},
$$

where $c_{i}$ is faction $i$ 's contribution cost.

Contrary to factions of interest, factions of principle, as they care about the overall ideological stance of the party, also care directly about how the other factions of principle influence the party manifesto. And, logically, any faction of principle would rather see other factions who are ideologically close to them influence the manifesto. Thus, for ideological factions, the objective function takes into account the influence of other factions, and the weight attached to each of the other factions' influence is decreasing in the (Euclidean) ideological distance between them and these other factions. In other words, there are externalities in their objective function. Faction $i=A, B, C$ solves the following 
problem:

$$
\max _{c_{i}} \frac{b_{i} c_{i}}{\sum_{m} b_{m} c_{m}} I+\left(1-d_{i j}\right) \frac{b_{j} c_{j}}{\sum_{m} b_{m} c_{m}} I+\left(1-d_{i k}\right) \frac{b_{k} c_{k}}{\sum_{m} b_{m} c_{m}} I-c_{i}
$$

where $d_{A C}=A-C=1, d_{A B}=B-0=B, d_{B C}=C-B=1-B$.

Given the above structure, intuition suggests that the type and position of both the leader and the factions influences the distribution of equilibrium factional contributions and rewards. This joint distribution is what determines the party's degree of unity or coherence behind its leader. For either factional type, we say that strong party unity is achieved if the mapping from the distance between the position of the leader and factions to their contributions and rewards is strictly decreasing in this distance: the more distant a faction is, the less it contributes and the less funds/influence it gets. Indeed, with such a decreasing mapping, the message the party and the leader send to voters is most coherent. If the mapping from distance to contributions and/or funds/influence is weakly decreasing in distance, we have weak party unity. If the mapping from distance to contributions and/or funds/influence is not monotonically decreasing in distance, we say that party unity is absent. ${ }^{14}$

The timing of the game is as follows:

1. The party selects its leader;

2. The three factions of each type contribute;

3. The three factions receive their reward which, together with the contributions, define the degree of party unity achieved;

4. The median voter observes, for each party, the location and type of the leader, the degree of party unity, the sum of factional contributions and then casts their ballot for the party they prefer.

\footnotetext{
${ }^{14}$ Using a continuous measure such as $\sum_{i}\left(1-d_{L i}\right) S h_{i}^{*}$ yields the same results as the mapping from distance to contributions and funds/influence for the factions that participate in the exchange turns out to be of three types only: 1) strictly decreasing in distance, 2) independent of distance; or 3) neither strictly decreasing in nor independent of distance.
} 
In what follows, in line with backward induction, we first solve for the factions' decisions given the type and position of the leader. With these factional decisions at hand, we can then analyse how easily and to what extent the party can meet its different goals through its strategic selection of the leader's position and type.

\section{Equilibrium Factional Behaviour}

\subsection{Factions of interest}

Suppose first that the leader is weak and thus the exchange procedure for the allocation of party funds is unbiased. All factions compete for the funds on an equal footing: $\forall i, b_{i}=1$. In such case, the share of the funds going to faction $i$ is exactly proportional to their contribution to the party, $c_{i}$ :

$$
S h_{i}=\frac{c_{i}}{\sum_{j} c_{j}}
$$

As a result, equilibrium behavior is symmetric, as each faction contributes equally and receives the same share of party funds:

Result 1. Suppose the leader is weak so that the exchange with factions of interest is unbiased. Then, for all $i=A, B, C$, we have:

- $c_{i}^{*}=\frac{2 V}{9}$;

- $S h_{i}^{*}=\frac{1}{3}$

The exchange between a weak leader and factions of interest reduces to a standard Tullock (1980) contest with identical players, in which the equilibrium contribution is increasing in the value of the available reward and decreasing in the number of participants in the contest.

What if the leader is authority charismatic? With such a leader, the exchange procedure is biased towards those factions that are closer to the leader, and equilibrium 
behaviour across factions is more involved. First of all, when one of the factions is too far from both the leader and the other two factions, this isolated faction decides not to contribute. The intuition for why this isolated player decides to drop out of the exchange is quite simply that they feel that the procedure is so biased against them that there is no point in participating in it. Further, whenever one faction does not participate in the exchange with the leader, the two active factions behave symmetrically, even though they are subject to different biases in the exchange procedure. ${ }^{15}$ This implies that the active faction which obtains the largest share of the party funds is the one whose bliss ideological point is closest to that of the leader. We thus have:

Result 2. Suppose the leader is authority charismatic. In any equilibrium in which only factions of interest $i$ and $j$ participate in the exchange with the leader, these two factions are the ones that are closest to the leader, and:

- $c_{i}^{*}=c_{j}^{*}=\frac{b_{i} b_{j}}{\left(b_{i}+b_{j}\right)^{2}} V$;

- Total contributions are maximised and equal to $V / 2$ when $L$ is equidistant to the two active factions, that is, when $L=B / 2$ (resp. $\left.L=\frac{1+B}{2}\right)$;

- $S h_{i}^{*}>S h_{j}^{*}$ if and only if $d_{L i}<d_{L j}$.

What if the positions of the three factions and the leader are such that all three factions actively participate in the exchange with the leader? Then we have the following equilibrium contributions and party fund shares: ${ }^{16}$

Result 3. Suppose the leader is authority charismatic. When all three factions of interest participate in equilibrium, we have:

1. If $B$ is closer to $L$ than $A$ (resp. $C$ ), then:

(a) B contributes most, followed by $A$ and then $C$ (resp. $C$ then $A$ );

\footnotetext{
${ }^{15}$ The fact that the contest between the two factions generates an equilibrium in which each faction chooses the same contribution (but their shares of the party funds are a function of their ideological distance to the leader) is a standard side product of contest models à la Tullock (1980).

${ }^{16}$ In the proof of this result in the Appendix, we pin down precisely all parameter configurations leading to all three factions being active.
} 
(b) $B$ also receives the largest share of party funds, followed again by $A$ and then $C$ (resp. C then $A)$.

2. If $B$ is further away from $L$ than $A$ (resp. $C)$, then:

(a) $A$ (resp. C) contributes most, followed by $B$ and then $C$ (resp. A);

(b) $A$ (resp. C) also receives the largest share of party funds, followed again by $B$ and then $C$ (resp. A).

Figure 1 is a stylised representation of all the equilibria of the exchange between an authority charismatic leader and factions of interest, as a function of the ideological position of $B$ and $L$. The figure also reports the ranking of factional contributions and fund shares.

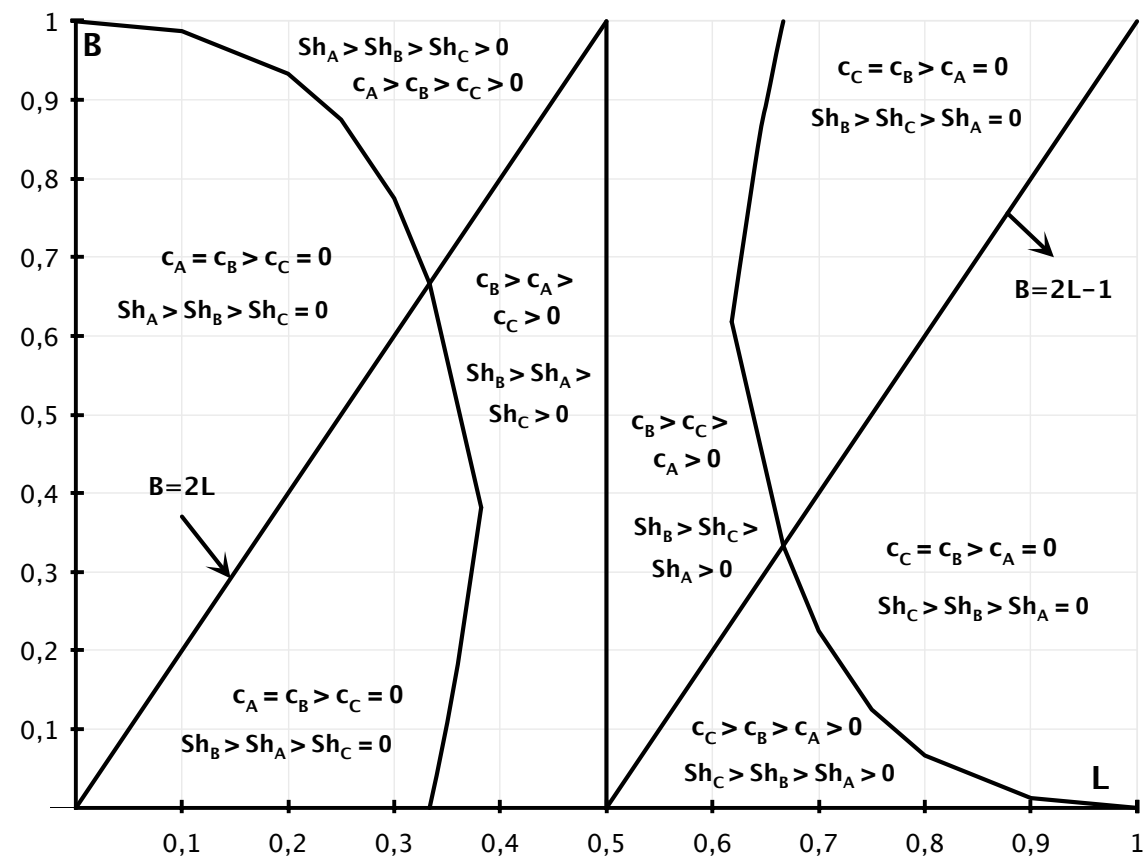

Figure 1: Contributions and fund shares of factions of interest

Let us focus on the left-hand half of the figure, as for the right-hand side of the figure the reasoning is symmetric. An intuition for the shapes and locations of the areas where the faction furthest away from $L$ is inactive is as follows. Imagine that $L$ is close to $A$, in 0.2 , say, and so is $B$, in 0.3 say. Then $C$ has a very low probability of receiving any 
funds because of his very low bias and the large biases that both $A$ and $B$ enjoy. As any contribution is costly to $C, C$ is better off dropping out of the exchange. Now move $B$ closer to $C$ and further away from $L$, keeping all else equal. Then the share of funds $C$ can hope to obtain increases because the leader favours $B$ less and $C$ (and $A$ ) relatively more (the bias of $B$ decreases hence the expected share of funds of $C$ increases because of the reduction in the denominator of $S h_{C}$ ). Hence, as $B$ gets closer to $C$, there can be a position of $B$ beyond which $C$ starts to participate in the exchange.

Let us now turn to the intuition for why the set in which only two factions are active has a missile-like shape. Focus on the area in the figure with $L$ around 0.35. Start from a point where all three factions are active, say at $B$ in 0.9 . Then, as $B$ gets closer to $L, B$ 's expected share of party funds increases, to reach a pinnacle for $B=L$. This must depress ( $A$ 's and) $C$ 's incentives to participate in the exchange (or more generally the incentives of the faction that is furthest from $L$ ), so that $C$ is inactive. Finally, $B$ 's bias starts to decrease as $B$ moves beyond 0.35 , so that $C$ has an incentive to participate.

\subsection{Factions of Principle}

How do factions of principle behave when their leader is weak and thus the exchange is unbiased? As with factions of interest, all factions are then on an equal footing. However, these factions care directly about how the other factions influence the manifesto, so we should expect the behaviour of factions not to be symmetric even when the exchange in unbiased. Indeed, when the leader is weak and thus the exchange is unbiased, we have:

Result 4. Suppose the leader is weak so that the exchange with factions of principle is unbiased. Then, in equilibrium we have:

- $c_{A}^{*}=c_{C}^{*}=\frac{I}{4}$ and $c_{B}^{*}=0$;

- $S h_{A}^{*}=S h_{C}^{*}=\frac{1}{2}$ and $S h_{B}^{*}=0$.

With factions of principle and when the leader is weak, only factions $A$ and $C$ actively participate in the exchange: $B$ does not find it worthwhile to participate, the two active 
factions behave symmetrically and are offered the same influence on the manifesto. ${ }^{17}$

The behaviour of the different factions of principle within the French Socialist party at the last presidential and legislative elections of 2017 are very much in line with this prediction: Benoit Hamon, the socialist leader, chose a markedly leftwing platform but turned out to be a very weak and electorally unappealing candidate. As predicted by our model, the faction of Manuel Valls, which was the one furthest away from that of the Socialist leader, was also the most active and vociferous in the election. The findings above also rationalise the struggles between Hillary Clinton and Bernie Sanders in the 2016 US Presidential election, who on many policy issues and ideas were quite clearly at opposite ends of the ideological spectrum within the Democratic party.

Suppose now that the leader is authority charismatic so that the exchange is biased towards those factions which are ideologically closer to the leader. As was the case for factions of interest, whenever one faction does not participate in party work in equilibrium, the two active factions behave symmetrically even though they are subject to different biases in the exchange procedure. Hence, the faction which ends up being most influential over the party manifesto is the one whose bliss ideological point is closest to the one of the leader, thereby contributing to party unity. We have:

Result 5. Suppose the leader is authority charismatic. In any equilibrium in which only two factions of principle $i$ and $j$ participate in the exchange with the leader, these two factions are the ones that are closest to the leader, and:

- $c_{i}^{*}=c_{j}^{*}=\frac{b_{i} b_{j} d_{i j}}{\left(b_{i}+b_{j}\right)^{2}} I$

- Total contributions are maximised and equal to $\frac{B I}{2}$ (resp. $\left.\frac{(B-1) I}{2}\right)$ when $L$ is equidistant to the two active factions, that is when $L=B / 2$ (resp. $\left.L=\frac{1+B}{2}\right)$;

- $S h_{i}^{*}>S h_{j}^{*}$ if and only if $d_{L i}<d_{L j}$;

\footnotetext{
${ }^{17}$ This result is reminiscent of similar findings in the economics corporate governance literature. See for example, Osborne et al. (2000) and Flamand and Troumpounis (2014), who provide two different but related formal models in which moderate individuals - like $B$ in our model - tend to not participate in costly meetings when participants are principled instead of interested, to use our factional terminology.
} 
What does participation look like when all three factions of principle are active? We have:

Result 6. Suppose the leader is authority charismatic. When all three factions of principle contribute, which can happen only if $B$ is closer to $L$ than $A$ (resp. C), we have:

1. If $A$ (resp. $C)$ and $B$ are on opposite ideological sides of $L$, then:

(a) A (resp. C) contributes most, followed by $B$ and then $C$ (resp. A);

(b) $B$ has the largest influence on the manifesto, followed by $A$ (or $C$ ) and then $C$ (or $A)$.

2. If $A$ (resp. $C$ ) and $B$ are on the same ideological side of $L$, then:

(a) $C$ (or A) contributes most, followed by $B$ and then $A$ (resp. $C$ );

(b) B has the largest influence on the party manifesto, followed by $A$ or $C$.

Figure 3 displays the set of equilibria with factions of principle.

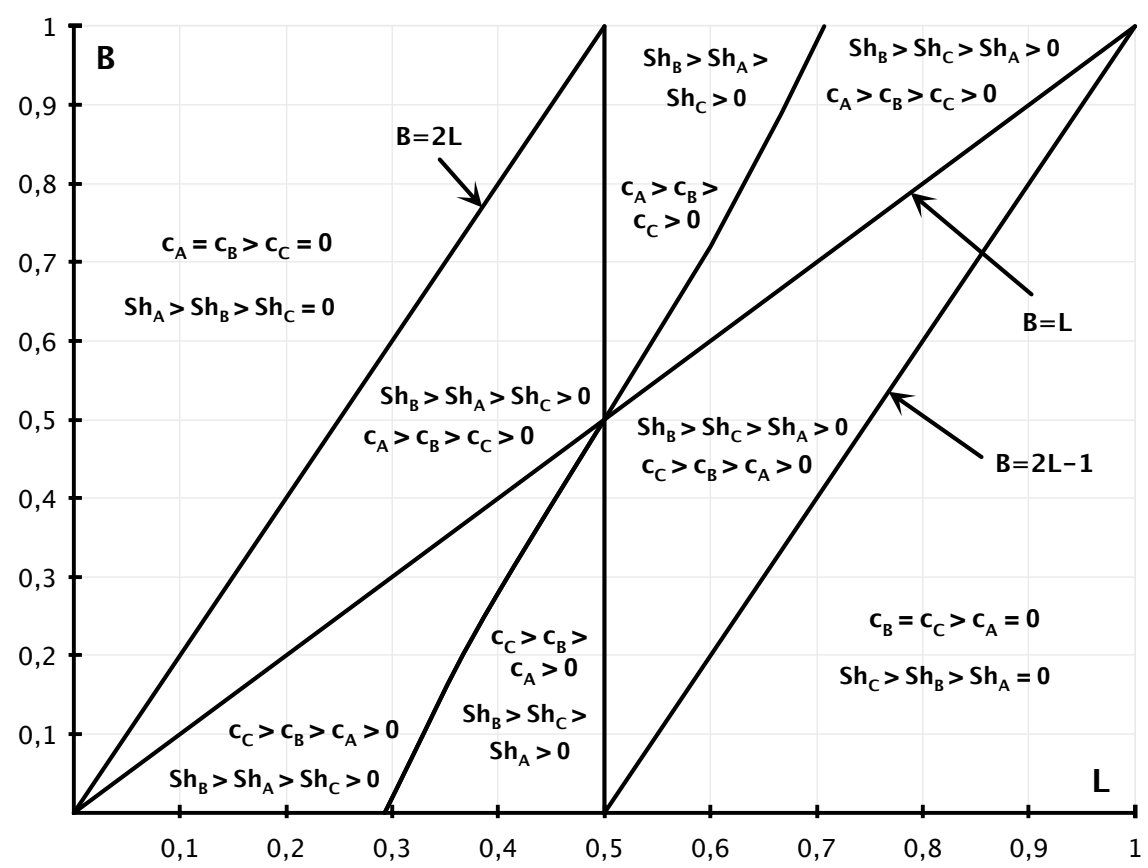

Figure 2: Contributions and influence shares of factions of principle 
Consider the left-hand side of the figure, where $L \in[0,1 / 2]$ (the right-hand side of the figure is symmetric). An intuition for the shapes and locations of the areas where $C$, the faction furthest away from $L$, is inactive is as follows. Imagine that $L$ is close to $A$, say at 0.2 . If $B$ is very close to $C$, say at 0.9 , it means that $C$ has high incentives to free-ride on $B$, as their ideology is very close, and $A$ and $B$ have low incentives to free-ride on each other, hence their contributions are rather large. Thus, it is not worthwhile for $C$ to contribute to the party cause. As $B$ moves closer to $A, C$ has lower incentives to free-ride on $B$, whereas $A$ and $B$ have higher incentives to free-ride on each other, meaning that their contribution decreases. The fact that the bias of $B$ increases reinforces this process, as it allows $B$ to reduce its contribution while keeping the same expected influence. After some point (namely when $B<2 L$ ), $C$ finds it worthwhile to devote some time and energy to the party cause. This mechanism goes on as $B$ moves even closer to $A$ until reaching the position of $L$, at which point the three factions contribute equally. Finally, when $B<L$, and thus $A$ and $B$ are very close to each other, it is $C$ that contributes the most: it has to compensate for the large biases in favour of $A$ and $B$, whose ideology it dislikes a lot.

Further, notice that faction $C$ is inactive in quite different situations than before. Indeed, with factions of interest, $C$ does not contribute when $L$ is too far from them, unless $B$ is quite close to $C$ so that $C$ does not feel isolated ideologically. To the contrary, with factions of principle, $C$ does not contribute if ( $L$ is too far from $C$ and) $B$ is quite close to $C$, as then $C$ can free-ride on $B$ 's contribution to see the manifesto being influenced along lines that $C$ does not dislike too much.

\section{$5 \quad$ Party choices and electoral success}

Having pinned down how factions behave as a function of the position and type of the party leader, we now turn to the main question of the paper: what party choices maximise its electoral success?

Examining how total contributions change with the type and position of the leader 
across the two types of factions, we have:

Proposition 1. Given any position of $B$ and $L$, a weak leader is always associated to higher total contributions than a strong leader is. Also, for any position of $B$ and $L$ and any leader type, factional contributions as a share of the available rewards ( $V$ or I) are always higher with factions of interest than with factions of principle.

Figure 3 illustrates this last finding for three different positions of $B$ under a charismatic leader. If factional contributions are electorally valuable - a maintained assumption in the literature on valence politics - then factions of interests are better than factions of principle for a party's electoral success. Indeed, for any given ideological position of $B$ and the party leader, factions of interests contribute more than factions of principle (as a fraction of the available rewards $V$ or $I$ ). Further, having a charismatic leader has a cost in terms of aggregate contributions as a result of the exchange being biased.
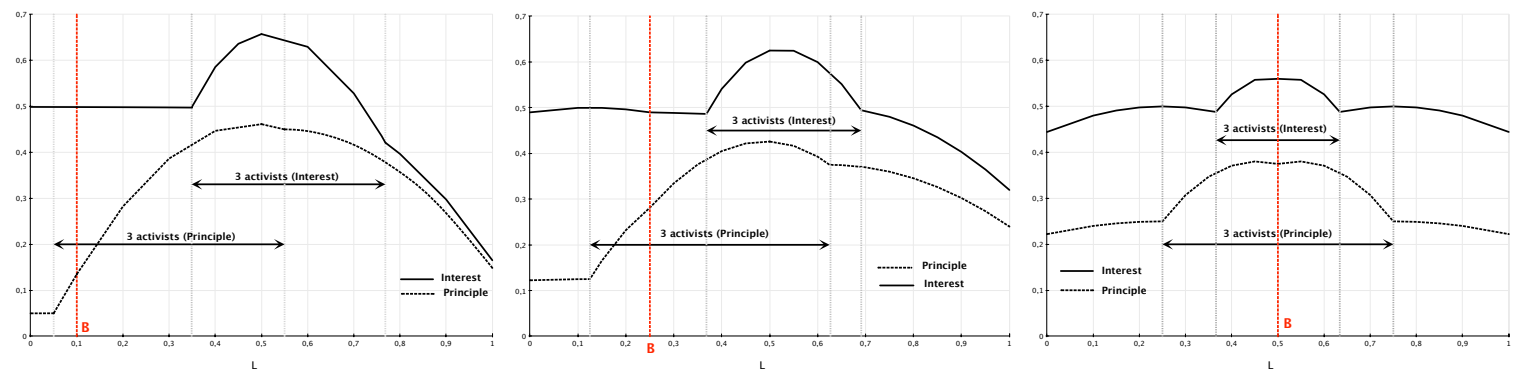

Figure 3: Total contributions

Let us now focus more directly on the choice of the type of leader. As our working assumption is that voters value charismatic leaders, having such a leader generates a direct electoral bonus for their party. What other effects do charismatic leaders have? We just found that a strong leader is associated to lower factional contributions that a weak one. Turning to party unity, we have:

Proposition 2. If the leader is weak, party unity is weak with factions of interest and absent with factions of principle.

With factions of principle, when the leader is weak, only the two factions that are furthest ideologically from the leader, $A$ and $C$, actively participate in the exchange: $B$ 
does not find it worthwhile to participate. Thus, with a weak leader and factions of principle, party unity is absent. The message to the electorate that comes out of the party manifesto is likely to be unclear and unappealing to voters, as the views that are contained in there are those of the two most distant factions and thus are somewhat incoherent, if not altogether incompatible.

As we said above, the behaviour of the different factions of principle within the French Socialist party at the last presidential and legislative elections of 2017 are very much in line with this prediction. The party thus appeared deeply divided to the voters' eye. And the end result was an incredibly dismal score in both the presidential and legislative elections. A similar story can be told about the electoral consequences for the democratic party of the bitter fighting between Hillary Clinton and Bernie sanders in the 2016 Presidential elections. Could the fact that Joe Biden managed to generate at least some support from the left wing of his party be part of his recipe for his Presidential success in 2020 ?

With factions of interest, party unity is weak, but this is because all three factions contribute the same and receive the same share of resources. In many respects, this is a situation that many real world parties could welcome. Even though no premium is given to factions that are ideologically closer to the leader, all factions in the party participate in the electoral effort. Thus, a weak leader can achieve full party mobilization, at least when factions are of interest.

Turning to the consequences of a strong leadership, we have:

Proposition 3. If the leader is strong:

- If two factions are active (irrespective of their type):

- party unity is strong if $L=B / 2$ (resp. $\left.L=\frac{1+B}{2}\right)$; and

- it is weak otherwise.

- If all factions of interest are active, party unity is strong;

- If all factions of principle are active, party unity is absent 
Thus, it is again with factions of interest that a party has most to win from having a strong leader. In particular, when all three factions are active, party unity is strong with factions of interest whereas it is absent with factions of principle. With factions of principle, the party can achieve strong party unity with a strong leader only if $L=B / 2$ (or $L=(1+B) / 2$ ) - only in a knife-edge case thus, which is also unlikely to coincide with the median voter's ideology - and at the cost of inducing one faction to be inactive. Indeed, with factions of principle, the party faces a trade-off between the desire to generate some party unity and having all three factions contribute. Such a trade-off is absent with factions of interest: for any possible position of faction $B$, there is always a range of leader positions that guarantees that the party achieves full party unity while having all three factions contribute. This is clear from Figure 4 below, in which the darker is an area, the lower is party unity in that area.
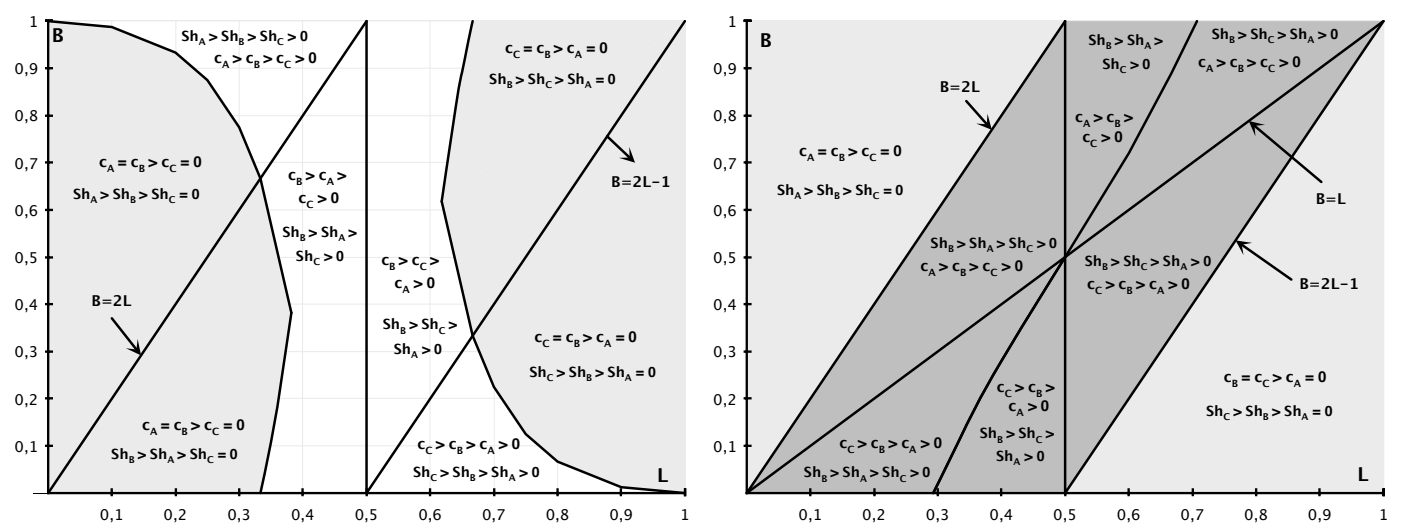

Figure 4: Party unity with factions of interest (left panel) and principle (right panel)

Observe that combining those graphs with those in Figure 3 suggests that, with factions of principle, there is also a trade-off between maximising total contributions and having at least some party unity: Figure 3 suggests that total contributions are maximized for a combination of positions of $B$ and $L$ that are associated with the party achieving no party unity at all, as shown in the right panel of Figure 4. Such a trade off appears to be absent with factions of interest. ${ }^{18}$

\footnotetext{
${ }^{18}$ The figures are suggestive only as in Figure 3 only three different positions of $B$ are taken into account.
} 
What about the ideological position of the leader? All parties would like to select a leader with an ideological position close or even equal to that of the median voter, if possible. What are the consequences of such a desire? We know that a weak leader's position impacts neither party unity - it is weak with factions of interest and absent with factions of principle - nor total contributions. To the contrary, a strong leader's position impacts both party unity and total contributions. Moreover, we know from propositions 1-3 that for any position of a strong leader, total contributions (as a fraction of the available rewards $V$ or $I$ ) and party unity are greater with factions of interest.

Our findings thus imply that under a strong leadership, parties with factions of interest find it less costly than parties with factions of principle to track closely the median voter's position. Indeed, with factions of interest, there is (at least some) party unity for any position of the strong leader, while there is no trade-off between maximising total contributions and having (at least some) party unity.

This complements the findings of Schumacher et al. (2013) on the determinants of the reactivity of parties to changes in the characteristics of the electorate. These authors contrast parties that are dominated by the party elite on the one hand and by party activists on the other. Our theory - in which the party as a whole chooses the leader and thus the leader selection process is not in the hands of the party elite only - adds that the type of factions that are present within parties also matters for how reactive parties can afford to be.

Another important consequence of the findings above is that parties are more likely to favor and sustain electoral systems that are more personalised if factions are of interest. These electoral systems increase the importance of having strong and charismatic leaders, and having such leaders is less costly with factions of interest. In fact, selecting a charismatic leader allows parties with factions of interest to foster party unity, even though there is a cost in terms of factional contributions. 


\section{Conclusion}

We developed and analysed a formal model of the intra-party exchange game the party leader plays with the party factions, to understand the conditions that are most conducive to electoral success. We analysed how this success is impacted by the position and strength of the leader and the position and type of the factions.

Our results imply that an uncharismatic leader is conducive to weak party unity at best, irrespective of the type of factions. Thus having such a leader is a double penalty for the party, as uncharismatic leaders are less valued than charismatic ones, and they do not generate party unity, whereas authority charismatic leaders can. This is especially true when the party's main factions are of principle, as the dramatic counter-performance of the French socialist party at the last Presidential and legislative elections in France in 2017 shows quite vividly. The only advantage a weak leader brings about is in terms of total contributions by factions, which are maximised under a weak leader. We also proved that when the leader is authority charismatic, party unity is more easily achieved with factions of interest than with factions of principle.

While we substantiated the findings of our model with important examples from recent electoral races in several countries such as France, the UK and the USA, we believe that our findings could be taken to the data in a more systematic manner, to further our understanding of the mapping from the pre-electoral choices of parties and their leaders to their post-election fates.

\section{References}

[1] Aldrich, John, (1983). "A Downsian Spatial Model with Party Activism". American Journal of Political Science 77: 974-990

[2] Andeweg, Rudy B. and Jacques Thomassen, (2010). "Pathways to party unity: Sanctions, loyalty, homogeneity and division of labour in the Dutch parliament". Party Politics 17: 655-672. 
[3] BBC Capital, (2017). "The art and science of being charismatic", 27 October 2017. Retrieved on the web at: http://www.bbc.com/capital/story/20171027-the-art-andscience-of-being-charismatic

[4] Bettcher, Kim Eric, (2005). "Factions of Interest in Japan and Italy: The Organizational and Motivational Dimensions of Factionalism". Party Politics 11: 339-358.

[5] Bittner, Amanda, (2011). Platform or Personality? The Role of Party Leaders in Elections. Oxford University Press.

[6] Butler, Daniel M. and Eleanor Neff Powell, (2014) "Understanding the Party Brand: Experimental Evidence on the Role of Valence." The Journal of Politics 76: 492-505.

[7] Ceron, Andrea, (2012). "Bounded oligarchy: how and when factions constrain leaders in party position-taking". Electoral Studies 31: 689-701.

[8] Ceron, Andrea (2019). Leaders, Factions and the Game of Intra-Party Politics. Routledge

[9] Clinton, Hillary, (2017). What Happened?

[10] Cross, William and Jean-Benoit Pilet, (2015). The Politics of Party Leadership. Oxford University Press.

[11] Dewan, Torun and David P. Myatt, (2007). "Leading the Party: Coordination, Direction, and Communication". American Political Science Review 101: 827-845.

[12] Dewan, Torun and David P. Myatt, (2008). "The Qualities of Leadership: Direction, Communication, and Obfuscation". American Political Science Review 102: 352-368.

[13] Dewan, Torun and Francesco Squintani, (2016). "In Defense of Factions". American Journal of Political Science 60: 860-881.

[14] De Winter, L., (1988). "Belgium: Democracy or oligarchy?" In M. Gallagher and M. Marsh (Eds.), Candidate selection in comparative perspective: The secret garden of politics (pp. 20-46). London, England: Sage. 
[15] Drugov, Mikhail and DmitryRyvkin (2017). "Biased contests for symmetric players". Games and Economic Behavior 103: 116-144.

[16] Flamand, Sabine and Orestis Troumpounis, (2014). "Participation quorums in costly meetings". Public Choice 159: 53-62.

[17] Greene, Zachary D. and Matthias Haber, (2014). "Leadership Competition and Disagreement at Party National Congresses". British Journal of Political Science 46: 611-632.

[18] Greene, Zachary D. and Matthias Haber, (2015). "The consequences of appearing divided: An analysis of party evaluations and vote choice". Electoral Studies 37: 15-27

[19] Harmel, R., H. Uk, A. Tan, and K. Janda (1995): "Performance, Leadership, Factions, and Party Change: An Empirical Analysis," West European Politics 18: 1-33.

[20] Hassell, Hans. J. G. (2016). "Party Control of Party Primaries: Party Influence in Nominations for the US Senate." Journal of Politics 78: 75-87.

[21] Invernizzi, Giovanna Maria and Prato, Carlo, (2019). "Power Sharing, Mobilization, and Party Organization". Available at SSRN: https://ssrn.com/abstract=3462071 or http://dx.doi.org/10.2139/ssrn.3462071

[22] Janda, K, (1980). Political Parties: A Cross-National Survey. The Free Press, New York.

[23] Karp, J. A., Banducci, S. A., and Shawn Bowler, (2007). "Getting out the vote: Party mobilization in a comparative perspective". British Journal of Political Science 38: $91-112$.

[24] Kernell, Georgia, (2015). "Party Nomination Rules and Campaign Participation". Comparative Political Studies 48: 1814-1843 
[25] Konig, Thomas, (2006): "The Scope for Policy Change after the 2005 Election: Veto Players and Intra-Party Decision Making". German Politics 15: 520-532.

[26] Levy, G. (2004): “A Model of Political Parties," Journal of Economic Theory 115: $250-77$.

[27] Lo, J., S.-O. Proksch, and J. B. Slapin (2014): "Ideological Clarity in Multiparty Competition: A New Measure and Test Using Election Manifestos," British Journal of Political Science 46: 591-610

[28] Marx, Paul and Gijs Schumacher, (2013). "Will to power? Intra-party conflict in social democratic parties and the choice for neoliberal policies in Germany, the Netherlands and Spain (1980-2010)". European Political Science Review 5: 151-173

[29] Miller, Gary and Norman Schofield, (2003). "Activists and Partisan Realignment in the United States". American Political Science Review 97: 245-260.

[30] Mutlu-Eren, Hande, (2015). "Keeping the Party Together". Public Choice 164: 117133.

[31] Osborne, Martin J., Jeffrey S. Rosenthal and Matthew Turner, (2000). "Meetings with costly participation". American Economic Review, 90: 927-943.

[32] Pattie, Charles J., Ronald J. Johnston and Edward A. Fieldhouse, (1995). "Winning the Local Vote: The Effectiveness of Constituency Campaign Spending in Great Britain, 1983-1992". American Political Science Review 89: 969-983.

[33] Persico Nicola, Pueblita J C. R. and Dan Silverman, (2011). "Factions and Political Competition". Journal of Political Economy 119: 242-288.

[34] Schofield, Norman, (2003). "Valence competition in the spatial stochastic model". Journal of Theoretical Politics 15: 371-383

[35] Schofield, Norman, (2006). "Equilibria in the spatial stochastic model of voting with party activists". Review of Economic Design 10: 183-203. 
[36] Schofield, Norman, Christopher Claassen, Ugur Ozdemir and Alexei Zakharov, (2011). "Estimating the effects of activists in two-party and multi-party systems: comparing the United States and Israel". Social Choice and Welfare 36: 483-518.

[37] Schofield Norman and I Sened (2005). "Modeling the interaction of parties, activists and voters: why is the political center so empty?" European Journal of Political Research 44: 355-390

[38] Schumacher, Gijs, C. de Vries and B. Vis (2013). "Understanding the Party Brand: Experimental Evidence on the Role of Valence". Journal of Politics 76: 492-505.

[39] Snyder James M. Jr et Michael Ting, (2002). "An Informational rationale for Political Parties". American Journal of Political Science 46: 90-110.

[40] Vivyan, Nick and Magnus Wagner, (2012). "Do voters reward rebellion? The electoral accountability of MPs in Britain". European Journal of Political Research 51: 235264.

[41] Ware, Alan (1996). Political Parties and Party Systems Oxford University Press.

[42] Wauters, Bram, Thijssen Peter, Van Aelst Peter, Pilet Jean-Benoit (2016). "Centralized personalization at the expense of decentralized personalization. The decline of preferential voting in Belgium (2003-2014)." Party Politics, 24: 511-523.

[43] Weber, Max, (1968). On Charisma and Institution Building. Chicago University Press

\section{Appendix: Proofs}

All the proofs that follow are for $L \in[0,1 / 2]$ and $B \in[0,1]$. The proofs for $L \in[1 / 2,1]$ are symmetric, one only needs to interchange $C$ and $A$.

Proof of Result 1. Faction $i=A, B, C$ chooses its contribution to party work by maximising 


$$
\frac{c_{i}}{\sum_{j} c_{j}} V-c_{i}
$$

The first order condition yields the best response

$$
c_{i}=\sqrt{\left(c_{j}+c_{k}\right) V}-c_{j}-c_{k}
$$

while the second order condition is satisfied:

$$
-\frac{2\left(c_{j}+c_{k}\right) V}{\left(c_{i}+c_{j}+c_{k}\right)^{3}}<0
$$

and thus

$$
c_{i}^{*}=\frac{2 V}{9} \text { and } S h_{i}^{*}=\frac{1}{3} \text { for all } i=A, B, C
$$

Proof of Result 2. As we show in the proof of Result 3 below, the two factions that are active are always the ones that are closest to the leader.

When only two factions are active, the game reduces to a contest with two players. Faction $i$ chooses its contribution to party work by maximising

$$
\frac{b_{i} c_{i}}{b_{i} c_{i}+b_{j} c_{j}} V-c_{i}
$$

The first order condition yields the best response

$$
c_{i}=\frac{1}{b_{i}} \sqrt{b_{i} b_{j} c_{j} V}-b_{j} c_{j}
$$

while the second order condition is satisfied:

$$
-\frac{2 b_{i}^{2} b_{j} c_{j} V}{\left(b_{i} c_{i}+b_{j} c_{j}\right)^{3}}<0
$$

and thus 


$$
c_{i}^{*}=c_{j}^{*}=\frac{b_{i} b_{j} V}{\left(b_{i}+b_{j}\right)^{2}}
$$

To prove that contributions are maximal for $L=B / 2$, we need to distinguish between the case $B<L$ and the case $B>L$. For $B<L, c_{i}=\frac{(1-L)(1-L+B) V}{(2-2 L+B)^{2}}$. It is then straightforward to check that $\frac{\partial c_{i}}{\partial L}<0$ for all $B<L$. Thus contributions decrease as $L$ moves away from $B$. For $L<B, c_{i}=\frac{(1-L)(1-B+L) V}{(2-B)^{2}}$. Then $\frac{\partial c_{i}}{\partial L}=\frac{B-2 L}{(2-B)^{2}} V$ which is negative for $L>B / 2$, positive for $L<B / 2$ and equal to zero for $L=B / 2$. There is thus a global maximum at $L=B / 2$.

Finally, the shares of party funds are given by

$$
S h_{i}^{*}=\frac{b_{i}}{b_{i}+b_{j}} \text { and } S h_{j}^{*}=\frac{b_{j}}{b_{i}+b_{j}}
$$

For $b_{i}=1-d_{L i}$ and $b_{j}=1-d_{L j}$, we have that $S h_{i}^{*}>S h_{j}^{*}$ if and only if $d_{L i}<d_{L j}$.

Proof of Result 3. Faction $i=A, B, C$ chooses its contribution to party work by maximising

$$
\frac{b_{i} c_{i}}{\sum_{j} b_{j} c_{j}} V-c_{i}
$$

The first order condition yields the best response

$$
c_{i}=\frac{1}{b_{i}}\left[\sqrt{b_{i}\left(b_{j} c_{j}+b_{k} c_{k}\right) V}-b_{j} c_{j}-b_{k} c_{k}\right]
$$

while the second order condition is satisfied:

$$
-\frac{2 b_{i}^{2}\left(b_{j} c_{j}+b_{k} c_{k}\right) V}{\left(b_{i} c_{i}+b_{j} c_{j}+b_{k} c_{k}\right)^{3}}<0
$$

and thus

$$
c_{i}^{*}=\frac{2 b_{j} b_{k}\left[b_{i}\left(b_{j}+b_{k}\right)-b_{j} b_{k}\right] V}{\left[b_{j} b_{k}+b_{i}\left(b_{j}+b_{k}\right)\right]^{2}}
$$




$$
S h_{i}^{*}=\frac{b_{i}\left(b_{j}+b_{k}\right)-b_{j} b_{k}}{b_{i}\left(b_{j}+b_{k}\right)+b_{j} b_{k}}
$$

where $b_{i}=1-d_{L i}$. If $B<L$, we have the following equilibrium contributions:

$$
\begin{gathered}
c_{A}^{*}=\frac{2(1+B-L) L\left[(1-L)^{2}+B(1-2 L)\right] V}{\left(1+B-L^{2}\right)^{2}} \\
c_{B}^{*}=\frac{2\left[B+(1-L)^{2}\right](1-L) L V}{\left(1+B-L^{2}\right)^{2}} \\
c_{C}^{*}=\frac{2(1+B-L)(1-L)[(4-3 L) L-1-B(1-2 L)] V}{\left(1+B-L^{2}\right)^{2}}
\end{gathered}
$$

We have that $c_{A}^{*}>0$ and $c_{B}^{*}>0$, while $c_{C}^{*}>0$ if and only if $B<\frac{3 L^{2}-4 L+1}{2 L-1}$. Observe that the latter condition is never satisfied for $L \leqslant 1 / 3$ - implying that faction $C$ does not contrbute - , while it is always satisfied for $L \geqslant \frac{1}{2}(3-\sqrt{5})$.

If $B>L$, we have the following equilibrium contributions:

$$
\begin{gathered}
c_{A}^{*}=\frac{2(1-B+L) L\left[1-3 L^{2}-B(1-2 L)\right] V}{[B-1-(2-L) L]^{2}} \\
c_{B}^{*}=\frac{2(1-L) L\left(1-B+L^{2}\right) V}{[B-1-(2-L) L]^{2}} \\
c_{C}^{*}=\frac{2(1-B+L)(L-1)[1-L(2+L)-B(1-2 L)] V}{[B-1-(2-L) L]^{2}}
\end{gathered}
$$

We have that $c_{A}^{*}>0$ and $c_{B}^{*}>0$, while $c_{C}^{*}>0$ if and only if $B>\frac{L^{2}+2 L-1}{2 L-1}$. Observe that the latter condition is always satisfied for $L \geqslant \frac{1}{2}(3-\sqrt{5})$.

Consider the parameter configurations in which all three factions are contributing to party work:

1. $L \leqslant \frac{1}{3}$ and $B>\frac{L^{2}+2 L-1}{2 L-1}$ 
2. $\frac{1}{3}<L<\frac{1}{2}(3-\sqrt{5})$ and $B<\frac{3 L^{2}-4 L+1}{2 L-1}$ or $B>\frac{L^{2}+2 L-1}{2 L-1}$

3. $\frac{1}{2}(3-\sqrt{5})<L \leqslant \frac{1}{2}$

If $B<L$, we have

$$
c_{A}^{*}-c_{B}^{*}=\frac{2 B L[1+B(1-2 L)+L(3 L-4)] V}{\left(1+B-L^{2}\right)^{2}}<0
$$

Indeed, let $K=1+B(1-2 L)+L(3 L-4)$. We have that $\frac{\partial K}{\partial B}=1-2 L>0$. For $B=\frac{3 L^{2}-4 L+1}{2 L-1}$, we have that $K=0$. For $B=0$, we have that $K=(1-L)(1-3 L)$, which is negative for all $L>1 / 3$. It follows that $K<0$ for all $B<\frac{3 L^{2}-4 L+1}{2 L-1}$.

$$
\begin{gathered}
c_{A}^{*}-c_{C}^{*}=\frac{2\left[B+(1-L)^{2}\right](1+B-L)(1-2 L) V}{\left(1+B-L^{2}\right)^{2}}>0 \\
c_{B}^{*}-c_{C}^{*}=\frac{2(1+B-2 L)(1-L)\left[(1-L)^{2}+B(1-2 L)\right] V}{\left(1+B-L^{2}\right)^{2}}>0
\end{gathered}
$$

It is direct that the above two expressions are positive for $B<L \leqslant 1 / 2$.

If $B>L$, we have

$$
c_{A}^{*}-c_{B}^{*}=\frac{2(2 L-B) L[1-L(2+L)-B(1-2 L)] V}{[B-1-(2-L) L]^{2}}>0 \text { if and only if } B>2 L
$$

Indeed, let $K=1-L(2+L)-B(1-2 L)$. We have that $\frac{\partial K}{\partial B}=2 L-1<0$. For $B=\frac{L^{2}+2 L-1}{2 L-1}$, we have that $K=0$. For $B=1$, we have that $K=-L^{2}<0$. Therefore, $K<0$ for all $B>\frac{L^{2}+2 L-1}{2 L-1}$, and thus $c_{A}^{*}-c_{B}^{*}>0$ if and only if $B>2 L$.

$$
c_{A}^{*}-c_{C}^{*}=\frac{2(1-B+L)(1-2 L)\left(1-B+L^{2}\right)}{[B-1-(2-L) L]^{2}}>0
$$

It is direct that the above expression is positive for $L \leqslant 1 / 2$ and $L<B<1$.

$$
c_{B}^{*}-c_{C}^{*}=\frac{2(1-B)(1-L)\left[1-B(1-2 L)-3 L^{2}\right] V}{[B-1-(2-L) L]^{2}}>0
$$


Indeed, let $K=1-B(1-2 L)-3 L^{2}$. We have that $\frac{\partial K}{\partial B}=2 L-1<0$. For $B=\frac{L^{2}+2 L-1}{2 L-1}$, we have that $K=2 L(1-L)>0$. For $B=1$, we have that $K=L(2-3 L)>0$. Therefore, $K>0$ for all $B>\frac{L^{2}+2 L-1}{2 L-1}$.

Therefore, we finally obtain that:

- $c_{A}^{*}>c_{B}^{*}>c_{C}^{*}$ if $B>2 L$

- $c_{B}^{*}>c_{A}^{*}>c_{C}^{*}$ if $B<2 L$

We know that for faction $i=A, B, C$, the equilibrium share of party funds is given by

$$
S h_{i}^{*}=\frac{b_{i}\left(b_{j}+b_{k}\right)-b_{j} b_{k}}{b_{i}\left(b_{j}+b_{k}\right)+b_{j} b_{k}}
$$

We have that $S h_{i}^{*}-S h_{j}^{*}=\frac{2\left(b_{i}-b_{j}\right) b_{k}}{b_{j} b_{k}+b_{i}\left(b_{j}+b_{k}\right)}$, from which it follows that $S h_{i}^{*}>S h_{j}^{*}$ if and only if $b_{i}>b_{j}$. Therefore, as the biases are linear in the distance:

- $S h_{A}^{*}>S h_{B}^{*}>S h_{C}^{*}$ if $B>2 L$

- $S h_{B}^{*}>S h_{A}^{*}>S h_{C}^{*}$ if $B<2 L$

Proof of Result 4. Faction $i=A, B, C$ chooses its contribution by maximising

$$
\frac{c_{i}}{\sum_{m} c_{m}} I+\frac{c_{j}}{\sum_{m} c_{m}} I\left(1-d_{i j}\right)+\frac{c_{k}}{\sum_{m} c_{m}} I\left(1-d_{i k}\right)-c_{i}
$$

The first order condition yields the best response

$$
c_{i}=\sqrt{\left(d_{i j} c_{j}+d_{i k} c_{k}\right) I}-c_{j}-c_{k}
$$

while the second order condition is satisfied:

$$
-\frac{2\left(c_{i} d_{i j}+c_{k} d_{i k}\right) I}{\left(c_{i}+c_{j}+c_{k}\right)^{3}}<0
$$


and thus

$$
c_{i}^{*}=\frac{2 d_{i j} d_{i k}\left(d_{i j}+d_{i k}-d_{j k}\right) d_{j k}^{2} I}{\left[d_{i j}^{2}+\left(d_{i k}-d_{j k}\right)^{2}-2 d_{i j}\left(d_{i k}+d_{j k}\right)\right]^{2}}
$$

Given that $d_{A B}=B, d_{B C}=1-B$ and $d_{A C}=1$, this yields:

$$
c_{A}^{*}=c_{C}^{*}=\frac{I}{4} \text { and } c_{B}^{*}=0
$$

and the equilibrium individual influences on the party manifesto are given by

$$
S h_{A}^{*}=S h_{C}^{*}=\frac{1}{2} \text { and } S h_{B}^{*}=0
$$

Proof of Result 5. Whenever one faction does not contribute to party work, the game reduces to a contest with two players. As we show in the proof of the next result, this can only happen if $L \leq B / 2$. Faction $i=A, B, C$ chooses its contribution by maximising

$$
\frac{b_{i} c_{i}}{b_{i} c_{i}+b_{j} c_{j}} I+\frac{b_{j} c_{j}}{b_{i} c_{i}+b_{j} c_{j}} I\left(1-d_{i j}\right)-c_{i}
$$

The first order condition yields the best response

$$
c_{i}=\frac{1}{b_{i}} \sqrt{b_{i} b_{j} d_{i j} c_{j} I}-b_{j} c_{j}
$$

while the second order condition is satisfied:

$$
-\frac{2 b_{i}^{2} b_{j} c_{j} d_{i j} I}{\left(b_{i} c_{i}+b_{j} c_{j}\right)^{3}}<0
$$

and thus

$$
c_{i}^{*}=c_{j}^{*}=\frac{b_{i} b_{j} d_{i j} I}{\left(b_{i}+b_{j}\right)^{2}} .
$$

Given that, as we show in the proof of the next result, only two factions contribute if and only if $L \leq B / 2$, replacing $b_{i}$ and $b_{j}$ by their values as a function of $L$ and $B$ yields 
immediately that $c_{i}$ is strictly increasing in $L$ and therefore contributions are maximized for $L=B / 2$.

Finally, the individual influences on the party manifesto are given by

$$
S h_{i}^{*}=\frac{b_{i}}{b_{i}+b_{j}} \text { and } S h_{j}^{*}=\frac{b_{j}}{b_{i}+b_{j}}
$$

As $b_{i}=1-d_{L i}$ and $b_{j}=1-d_{L j}$, we have that $S h_{i}^{*}>S h_{j}^{*}$ if and only if $d_{L i}<d_{L j}$.

Proof of Result 6. Faction $i=A, B, C$ chooses its contribution by maximising

$$
\frac{b_{i} c_{i}}{\sum_{m} b_{m} c_{m}} I+\frac{b_{j} c_{j}}{\sum_{m} b_{m} c_{m}} I\left(1-d_{i j}\right)+\frac{b_{k} w_{k}}{\sum_{m} b_{m} c_{m}} I\left(1-d_{i k}\right)-c_{i}
$$

The first order condition yields the best response

$$
c_{i}=\frac{1}{b_{i}}\left[\sqrt{b_{i}\left(d_{i j} b_{j} c_{j}+d_{i k} b_{k} c_{k}\right) I}-b_{j} c_{j}-b_{k} c_{k}\right]
$$

while the second order condition is satisfied:

$$
-\frac{2 b_{i}^{2}\left(b_{j} c_{j} d_{i j}+b_{k} c_{k} d_{i k}\right) I}{\left(b_{i} c_{i}+b_{j} c_{j}+b_{k} c_{k}\right)^{3}}<0
$$

and thus

$$
\begin{aligned}
& c_{i}^{*}=\frac{2 b_{j} b_{k} d_{i j} d_{i k} d_{j k}^{2}\left(b_{i} b_{j} d_{i j}+b_{i} b_{k} d_{i k}-b_{j} b_{k} d_{j k}\right) I}{\left[b_{i}\left(d_{i j}-d_{i k}\right)\left(b_{j} d_{i j}-b_{k} d_{i k}\right)-\left(b_{j}\left(b_{i}+b_{k}\right) d_{i j}+b_{k}\left(b_{i}+b_{j}\right) d_{i k}\right) d_{j k}+b_{j} b_{k} d_{j k}^{2}\right]^{2}} \\
& S h_{i}^{*}=\frac{d_{j k}\left[b_{j} b_{k} d_{j k}-b_{i}\left(b_{j} d_{i j}+b_{k} d_{i k}\right)\right]}{b_{i}\left(d_{i j}-d_{i k}\right)\left(b_{j} d_{i j}-b_{k} d_{i k}\right)-\left[b_{j}\left(b_{i}+b_{k}\right) d_{i j}+b_{k}\left(b_{i}+b_{j}\right) d_{i k}\right] d_{j k}+b_{j} b_{k} d_{j k}^{2}}
\end{aligned}
$$

If $B<L$, we have the following equilibrium contributions:

$$
\begin{gathered}
c_{A}^{*}=\frac{(1+B-2 L) L I}{2(1+B-L)} \\
c_{B}^{*}=\frac{(1-L) L[1+B(1-2 L)-2(1-L) L] I}{2(1-B)(1+B-L)^{2}}
\end{gathered}
$$




$$
c_{C}^{*}=\frac{(1-L)[2(1-L) L-B(1+B-2 L)] I}{2(1-B)(1+B-2 L)}
$$

and thus $c_{i}^{*}>0$ for all $i=A, B, C$.

If $B>L$, we have the following equilibrium contributions:

$$
\begin{gathered}
c_{A}^{*}=\frac{L[2 L(B-L)-(1-B) B] I}{2 B(1-B+L)} \\
c_{B}^{*}=\frac{(1-L)[B-2 L(B-L)] I}{2 B(1-B+L)^{2}} \\
c_{C}^{*}=\frac{(2 L-B)(1-L) I}{2(1-B+L)}
\end{gathered}
$$

and thus $c_{A}^{*}>0$ and $c_{B}^{*}>0$, while $c_{C}^{*}>0$ if and only if $B<2 L$.

Consider the parameter configurations such that all three factions are active, hence $B<2 L$. If $B<L$ we have:

$$
c_{A}^{*}-c_{B}^{*}=\frac{(B-L)[2 L(1+B-L)-B(1+B)] I}{2(1-B)(1+B-L)^{2}}<0
$$

Indeed, let $K=2 L(1+B-L)-B(1+B)$. We have that $\frac{\partial K}{\partial B}=2(L-B)-1<0$. For $B=0$, we have that $K=2 L(1-L)>0$. For $B=L$, we have that $K=L(1-L)>0$. Therefore, $K>0$ for all $B<L$.

$$
c_{A}^{*}-c_{C}^{*}=\frac{(L-B)[2 L(1+B-L)-(1+B)] I}{2(1-B)(1+B-L)}<0
$$

Indeed, let $K=2 L(1+B-L)-(1+B)$. We have that $\frac{\partial K}{\partial B}=2 L-1<0$. For $B=0$, we have that $K=2 L(1-L)-1<0$. For $B=L$, we have that $K=L-1<0$. Therefore, $K<0$ for all $B<L$.

$$
c_{B}^{*}-c_{C}^{*}=\frac{(1+B)(1+B-2 L)(L-B)(1-L) I}{2(B-1)(1+B-L)^{2}}<0
$$


It is direct that the above expression is negative for $B<L \leqslant 1 / 2$.

If $B>L$ we have:

$$
\begin{gathered}
c_{A}^{*}-c_{B}^{*}=\frac{(2-B)(2 L-B)(B-L) L I}{2 B(1-B+L)^{2}}>0 \\
c_{A}^{*}-c_{C}^{*}=\frac{(B-L)\left[B(1-2 L)+2 L^{2}\right] I}{2 B(1+L-B)}>0 \\
c_{B}^{*}-c_{C}^{*}=\frac{(B-L)(1-L)[B(1-B)+2 L(B-L)] I}{2 B(1-B+L)^{2}}>0
\end{gathered}
$$

It is direct that the three above expressions are positive for $L<B<2 L \leqslant 1$. And thus:

1. If $B<L$, we have $c_{C}^{*}>c_{B}^{*}>c_{A}^{*}$

2. If $B>L$, we have $c_{A}^{*}>c_{B}^{*}>c_{C}^{*}$

Further, if $B<L$, the equilibrium influences on the party manifesto are given by

$$
\begin{gathered}
S h_{A}^{*}=\frac{1+B-2 L}{2(1+B-L)} \\
S h_{B}^{*}=\frac{(B+1)-2 L(1+B-L)}{2(1-B)(1+B-L)} \\
S h_{C}^{*}=\frac{2 L(1+B-L)-B(1+B)}{2(1-B)(1+B-L)}
\end{gathered}
$$

and thus we have

$$
S h_{A}^{*}-S h_{B}^{*}=\frac{2 L(2 B-L)-B(B+1)}{2(1-B)(1+B-L)}<0
$$

Indeed, let $K=2 L(2 B-L)-B(B+1)$. We have that $\frac{\partial K}{\partial L}=4(B-L)<0$. For $L=B$, we have that $K=B(B-1)<0$. For $L=1 / 2$, we have that $K=B(1-B)-1 / 2<0$. Therefore, $K<0$ for all $B<L \leqslant 1 / 2$. 


$$
S h_{A}^{*}-S h_{C}^{*}=\frac{2 L(L-2)+1+B}{2(1-B)(1-L)}>0 \text { if and only if } B>4 L-2 L^{2}-1
$$

Indeed, let $K=2 L(L-2)+1+B$. We have that $\frac{\partial K}{\partial B}=1>0$. For $B=4 L-2 L^{2}-1$, we have that $K=0$. For $B=L$, we have that $K=1+L-2 L(2-L)>0$. Therefore, $K>0$ for all $B>4 L-2 L^{2}-1$.

$$
S h_{B}^{*}-S h_{C}^{*}=\frac{(1+B-2 L)^{2}}{2(1-B)(1+B-L)}>0
$$

It is direct that the above expression is positive for $B<L \leqslant 1 / 2$.

Finally, if $B>L$, the equilibrium influences on the party manifesto are given by

$$
\begin{gathered}
S h_{A}^{*}=\frac{2 L(B-L)+B(1-B)}{2 B(1-B+L)} \\
S h_{B}^{*}=\frac{B-2 L(B-L)}{2 B(1-B+L)} \\
S h_{C}^{*}=\frac{2 L-B}{2(1-B+L)}
\end{gathered}
$$

and thus we have

$$
S h_{A}^{*}-S h_{B}^{*}=-\frac{(B-2 L)^{2}}{2 B(1-B+L)}<0
$$

It is direct that the above expression is negative for $L<B<2 L \leqslant 1$.

$$
S h_{A}^{*}-S h_{C}^{*}=\frac{B-2 L^{2}}{2 B(1-B+L)}>0
$$

It is direct that the above expression is positive for $L<B<2 L \leqslant 1$.

$$
S h_{B}^{*}-S h_{C}^{*}=\frac{B(1+B)-2 L(2 B-L)}{2 B(1-B+L)}>0
$$

Indeed, let $K=B(1+B)-2 L(2 B-L)$. We have that $\frac{\partial K}{\partial L}=4(L-B)<0$. For $L=0$, we have that $K=B(B+1)>0$. For $L=B$, we have that $K=B(1-B)>0$. 
Therefore, $K>0$ for all $L<B$.

Therefore:

- If $B<4 L-2 L^{2}-1$, we have $S h_{B}^{*}>S h_{C}^{*}>S h_{A}^{*}$

- If $B>4 L-2 L^{2}-1$, we have $S h_{B}^{*}>S h_{A}^{*}>S h_{C}^{*}$

Proof of Proposition 1. First we will show that total contributions are always higher under a weak leader than under a charismatic one. We start with factions of interest. The fact that total contributions are higher when the contest is not biased is a direct application of standard results in the theory of Tullock contests; see for example Drugov and Ryvkin (2017) and the references therein.

Things are less straightforward when factions are of principle, as this scenario is understudied in the theory of contests. If the leader is weak, only factions of interest $A$ and $C$ are active and total effort is given by $E_{W}^{*}=\frac{I}{2}$.

If the leader is strong and all three factions are active, we have two cases to consider. First, if $B<L$, total effort is given by

$$
E_{S}^{*}=\frac{B^{3}+B^{2}(2-4 L)+4 L(L-1)^{3}+B[1-4 L(L-2)(L-1)]}{2(B-1)(1+B-L)^{2}} I .
$$

The above total effort turns out to be strictly smaller than $\frac{I}{2}$. Indeed, we have that

$$
E_{S}^{*}-\frac{I}{2}=\frac{B^{2}(1-2 L)+\left(1-3 L+2 L^{2}\right)^{2}+B\left(2-8 L+11 L^{2}-4 L^{3}\right)}{2(B-1)(1+B-L)^{2}} I
$$

and the three terms in the sum in the numerator are positive for $L \leqslant 1 / 2$ and $B \in[0,1]$ whereas the denominator is negative, given that $B \leq 1 / 2$. Hence $E_{S}^{*} \leqslant I / 2$.

Second, If $L \leq B<2 L$, we have

$$
E_{S}^{*}=\frac{B^{3}-4 L^{4}-B^{2}(1+4 L)+4 B L\left(1+L^{2}\right)}{2 B(1-B+L)^{2}} I,
$$


which is again smaller than $\frac{I}{2}$. Indeed, $E_{S}^{*}-I / 2$ is negative if

$$
\begin{gathered}
2 B^{3}-8 L^{4}-2 B^{2}(1+4 L)+8 B L\left(1+L^{2}\right)-2 B(1-B+L)^{2}<0 \\
\Longleftrightarrow 4 B L\left[2 L^{2}-B\right]-8 L^{4}+B[2 L(2-L)-2(1-B)]<0
\end{gathered}
$$

which is always true. Indeed, $2 L^{2}-B \leq 0$ for any $L \leqslant 1 / 2$ and $L<B<2 L$ as $2 L^{2} \leq L$ for $L \leqslant 1 / 2$; also, even though the term $B[2 L(2-L)-2(1-B)]$ is increasing in $B$, even for $B=2 L, 8 L^{2}\left[2 L^{2}-2 L\right]-8 L^{4}+2 L[2 L(2-L)-2(1-2 L)] \leq 0$.

Finally, we know from Result 5 that when faction $C$ is inactive, total contributions are at most equal to $B I / 2$. Given that $B \in[0,1]$, this concludes the proof of the first statement of Proposition 1.

We now turn to the comparison of total contributions across factions. That is, we want to show that factions of interest always contribute more than factions of principle. For any positions of $B$ and $L$ such that the number of active factions of interest is equal to the number of active factions of principle, we can rely on the first order condition to the factions' problem; see the proofs of results $2,3,5$ and 6 . It is then immediate to see that factions of interest contribute more (as a fraction of the available rewards) given that the (marginal) cost of effort is the same for both types of factions, namely $c_{i}$, whereas the (marginal) benefit of contributing is strictly greater for factions of interest.

To prove that total contributions are still higher (as a fraction of the available rewards) with factions of interest for values of $B$ and $L$ such that only two of them contribute but three factions of principle are active (this happens if $B<2 L$ and $B$ inside the missileshaped area), we proceed as follows. We know that total contributions (as a fraction of $V)$ of the two factions of interest are equal to $2 \frac{(1-L)(1-L+B)}{(2-2 L+B)^{2}}$ if $B<L$ and to $2 \frac{(1-L)(1-B+L)}{(2-B)^{2}}$ if $B>L$. For factions of principle, total contributions (as a fraction of $I$ ) are given by $\frac{B^{3}+B^{2}(2-4 L)+4 L(L-1)^{3}+B[1-4 L(L-2)(L-1)]}{2(B-1)(1+B-L)^{2}}$ if $B<L$, and by $\frac{B^{3}-4 L^{4}-B^{2}(1+4 L)+4 B L\left(1+L^{2}\right)}{2 B(1-B+L)^{2}}$ if 
$B>L$. We thus need to show that:

$$
2 \frac{(1-L)(1-L+B)}{(2-2 L+B)^{2}}>\frac{B^{3}+B^{2}(2-4 L)+4 L(L-1)^{3}+B[1-4 L(L-2)(L-1)]}{2(B-1)(1+B-L)^{2}}
$$

if $B<L$, and

$$
2 \frac{(1-L)(1-B+L)}{(2-B)^{2}}>\frac{B^{3}-4 L^{4}-B^{2}(1+4 L)+4 B L\left(1+L^{2}\right)}{2 B(1-B+L)^{2}}
$$

if $B>L$.

Re-writing the first inequality, we need to show that

$$
1>\frac{(1-L+B / 2)^{2}\left(B^{3}+B^{2}(2-4 L)+4 L(L-1)^{3}+B[1-4 L(L-2)(L-1)]\right)}{(1-L)(B-1)(1+B-L)^{3}}
$$

which is always true as $\frac{(1-L+B / 2)^{2}}{(1-L)(1+B-L)} \in[1,2]$ for $L \leqslant \frac{1}{2}(3-\sqrt{5})$ and $B<L$ and we know from above that $\frac{B^{3}+B^{2}(2-4 L)+4 L(L-1)^{3}+B[1-4 L(L-2)(L-1)]}{2(B-1)(1+B-L)^{2}}<1 / 2$.

For $B>L$, we need to show that

$$
2 \frac{(1-L)(1-B+L)}{(2-B)^{2}}>\frac{B^{3}-4 L^{4}-B^{2}(1+4 L)+4 B L\left(1+L^{2}\right)}{2 B(1-B+L)^{2}}
$$

Simple but tedious algebra proves that the above is true for both $B=L$ and $B=2 L$ (or the relevant upper bound on $B$ when $L$ approaches $\frac{1}{2}(3-\sqrt{5})$ ). The LHS is strictly increasing in $B$ as long as $B<2 L$, which always holds. Additional tedious algebra confirms that the RHS is strictly decreasing in $B$. The above inequality thus holds for any admissible values of $B$ and $L$.

Finally, we need to prove that total contributions are still higher (as a fraction of the available rewards) with factions of interest for values of $B$ and $L$ such that all three of them contribute but only two factions of principle are active (this happens if $B>2 L$ and $B$ outside the missile-shaped area). We need to show that:

$$
\frac{2 B\left[1+L\left(4 L^{2}-4+L\right)\right]+L[4+L(2-L(4+5 L))]-1-B^{2}(1-2 L)^{2}}{[B-1-(2-L) L]^{2}}>\frac{B(1-B+L)(1-L)}{(2-B)^{2}}
$$


Given the subset of the parameter space we are focusing on, the denominator of the RHS is larger than that of the LHS of the inequality. A comparison of the numerators thus suffices to prove that the above inequality always holds. Sarting with the terms in the numerator on the LHS, $B^{2}(1-2 L)^{2}$ is always smaller than $B^{2}$ for $L \leqslant 1 / 2$. Also, $L\left(4 L^{2}-4+L\right)$ is negative but never smaller than -1 , hence $2 B\left[1+L\left(4 L^{2}-4+L\right)\right]-1-B^{2}(1-2 L)^{2}>$ $2 B-1-B^{2}$, which is greater than the numerator of the RHS. As $L[4+L(2-L(4+5 L))]$ is strictly positive for any $L \leqslant 1 / 2$, this concludes the proof.

Proof of Proposition 2. Direct from the ranking of factional efforts and rewards (Result 1 to 6$)$. 